\title{
Kesan Model Unsur Tautan Terhadap Pengajaran Karangan Bahasa Melayu
}

\author{
ZAMRI SALLEH \\ Sekolah Menengah Kebangsaan Batu 5, Gurun \\ ABDULL SUKOR SHAARI \\ Universiti Utara Malaysia
}

\begin{abstract}
ABSTRAK
Kajian ini dijalankan untuk melihat sama ada pengajaran unsur tautan dengan menggunakan Model Pengajaran Unsur Tautan dapat digunakan oleh guru sebagai salah satu teknik dalam menghasilkan karangan yang berkualiti. Tinjauan terhadap karya terdahulu mendapati bahawa tautan (kohesi) lebih menarik minat pengkaji luar negara berbanding dengan pengkaji tempatan. Kajian ini dijalankan terhadap 60 orang murid tingkatan tiga di sebuah sekolah menengah di Kedah. Mereka dibahagikan kepada dua kumpulan, iaitu 30 orang dalam kumpulan eksperimen dan selebihnya dalam kumpulan kawalan. Kajian ini menggunakan reka bentuk kuasi eksperimen (Quasi-Experimental Design). Untuk menentukan sama ada terdapat perbezaan yang signifikan antara jumlah unsur tautan murid kumpulan eksperimen dengan jumlah unsur tautan murid kumpulan kawalan pada peringkat ujian pra dan ujian pasca, ujian-t sampel bebas (independent samples t-test) dijalankan dengan menggunakan perisian SPSS for Windows Version 11.5. Dapatan kajian menunjukkan pengajaran unsur tautan memberikan kesan terhadap jumlah unsur tautan yang dihasilkan oleh murid.
\end{abstract}

\section{ABSTRACT}

Purpose - This study examine whether the teaching of cohesive ties using "The Cohesive Ties Teaching Model" can be used by teachers as a technique in writing quality essays.

Method - This study was carried out using the Quasi-Experimental Design. Sample essays were collected from 60 Form Three students 
in a secondary school in Kedah. They were divided into two groups, 30 students were placed in experimental group, and the rest were placed in control group. To ascertain whether there is a significant difference between the scores of frequency in cohesive ties among the experimental and control groups in pre-test and post-test, the independent samples t-test was conducted using the SPSS for Windows Version 11.5.

Findings - The finding of this study proved that the teaching of cohesive ties has given a significant effect on the scores of frequency in cohesive ties made by students in their essays.

Value - This study extends the Bahasa Melayu education (especially in teaching and learning field) about the effectiveness of using The Cohesive Ties Teaching Model as a technique in writing quality essays.

Keywords - Quasi-experimental design, The cohesive Ties teaching model, Technique in teaching writing, Quality essays

\section{PENGENALAN}

Kemahiran menulis merupakan salah satu daripada komponen kemahiran bahasa yang tersenarai dalam kurikulum Bahasa Melayu sekolah di Malaysia, baik pada peringkat sekolah rendah mahupun pada peringkat sekolah menengah. Kandungan dalam Sukatan Pelajaran Bahasa Melayu Sekolah Menengah (2003) menyatakan kemahiran menulis merujuk kepada keupayaan murid mengeluarkan idea melalui pelbagai jenis penulisan yang berkaitan dengan ilmu pengetahuan dan pengalaman peribadi yang telah dilalui dengan menggunakan ayat yang gramatis, tanda baca dan ejaan yang betul, serta tulisan yang jelas dan kemas. Murid juga digalakkan untuk menggunakan kreativiti mereka untuk menghasilkan penulisan bahan ilmu dan imaginatif.

Sehubungan itu, aspek pengajaran dan pembelajaran kemahiran menulis di bilik darjah perlu mendapat perhatian yang sewajarnya oleh para pendidik dan ahli bahasa. Pengajaran karangan sepatutnya dipelbagaikan dan tidak hanya menggunakan kaedah biasa, iaitu guru memberikan soalan, diikuti oleh perbincangan 
isi penting dan murid dikehendaki menulis karangan. Pengajaran tatabahasa ayat berdasarkan Teori Transformasi Generatif yang menekankan penggunaan rumus tatabahasa yang betul pula didapati menjadi agenda utama oleh para guru Bahasa Melayu. Guru sering menekankan aspek betul atau salah sesuatu penggunaan kata, frasa, atau ayat dalam karangan dan jarang sekali menekankan aspek wacana dalam pengajaran mereka. Oleh itu, kajian ini dijalankan sebagai usaha untuk cuba menunjukkan bahawa pengajaran unsur tautan dapat digunakan oleh guru sebagai salah satu teknik dalam menghasilkan karangan yang kohesif dan koheren.

\section{LATAR BELAKANG KAJIAN}

Kajian ini dijalankan kerana para pelajar didapati masih lemah dalam kemahiran menulis. Walaupun pelajar didedahkan dengan banyak teknik mengarang, didapati karangan pelajar masih tidak mempunyai keutuhan wacana kerana aspek tautan (kohesi) kurang diberi penekanan dalam pengajaran dan pembelajaran bahasa. Hal ini menyebabkan karangan mereka longgar serta tidak kohesif akibat kurangnya unsur tautan dalam karangan mereka. Menurut Abdul Jalil Othman (2000), kebanyakan pelajar tidak mengetahui teknik menulis karangan dengan betul. Mereka kurang diberi pendedahan tentang cara menghasilkan karangan yang benar-benar mantap, bukan sahaja dari segi penggunaan bahasa yang betul, tetapi juga dari segi gaya penulisan yang teratur dan menepati ciri penulisan karangan yang sebenarnya.

Walaupun terdapat saranan daripada beberapa pengkaji terdahulu seperti Khathijah Abdul Hamid (2001), Wong Khek Seng (1993) dan Sanat Md. Nasir (2002) agar tautan diajarkan dalam mata pelajaran Bahasa Melayu di sekolah, namun sehingga kini, isi kandungan tatabahasa dalam sukatan pelajaran sedia ada hanya menyentuh aspek morfologi (kata) dan sintaksis (ayat) sahaja, sedangkan matlamat pengajaran dan pembelajaran bahasa Melayu sekolah menengah adalah untuk menyediakan murid bagi menguasai kecekapan berbahasa dan berkomunikasi yang memerlukan pengetahuan tentang wacana.

Menurut Khathijah Abdul Hamid (2001) dan Azhar M. Simin (1988), pengajaran tatabahasa ayat sekadar mengajar murid tentang imbuhan (morfologi) dan sintaksis yang terbatas kepada 
satu ayat sahaja secara gabung jalinan atau secara konteks seperti tatabahasa yang diajarkan secara bergabung dengan kemahiran membaca, iaitu dalam bacaan dan pemahaman, ataupun dengan pengajaran tatabahasa tersendiri tentang rumus tatabahasa dalam sesuatu ayat. Pengajaran seperti ini terbatas kepada satu ayat tanpa melihat perkaitan dan kesepaduan dari segi kebahasaan dalam teks karangan, pelbagai bentuk retorik yang memungkinkan penggunaan pelbagai sarana kohesi dan koheren. Menurut Beaugrande dan Dressler (1994), dari segi kemahiran menulis, tatabahasa ayat hanya menekankan setakat permukaan seperti tanda bacaan, subject-verb agreement, dan susunan ayat.

Penelitian terhadap kajian terdahulu mendapati bahawa amat kurang kajian dijalankan tentang unsur tautan dalam pengajaran bahasa Melayu. Para pengkaji seperti Wong Khek Seng (1993), Musmira Sa'ad (1995), dan Sanat Md. Nasir (2002) menumpukan aspek analisis tautan dalam genre seperti novel, cerpen dan akhbar. Pengkaji yang berminat dengan unsur tautan dalam pengajaran dan pembelajaran bahasa Melayu di Malaysia hanya sedikit berbanding dengan bidang-bidang bahasa yang lain.

Oleh sebab aspek tautan dipelopori oleh para pengkaji bahasa Inggeris, maka masalah untuk menentukan istilah yang sesuai digunakan dalam pengajaran dan pembelajaran bahasa Melayu di bilik darjah merupakan sesuatu yang agak rumit. Oleh itu, penggunaan istilah yang dipermudah amat penting bagi memastikan unsur tautan dapat diajarkan di peringkat sekolah rendah dan di sekolah menengah (Khathijah Abdul Hamid, 2001).

Minat para pengkaji tentang aspek kohesi (tautan) dan koheren dalam pengajaran dan pembelajaran bahasa bahasa Inggeris sebagai bahasa kedua (ESL) semakin meningkat disebabkan oleh perubahan daripada tatabahasa ayat kepada teks atau tatabahasa wacana. Dalam konteks bahasa Melayu pula, Nik Safiah Karim, Hashim Musa, Hamid Mahmood dan Farid M. Onn (2008) juga telah memasukkan elemen wacana sebagai berada dalam tingkat yang tertinggi dalam hierarki tatabahasa selepas kata, frasa, klausa, dan ayat. Menurut mereka, kohesi (tautan) dan koheren (runtutan) merupakan dua ciri wacana yang utama. Oleh itu, kajian tentang tautan (kohesi) dalam pengajaran dan pembelajaran bahasa Melayu ini amat sesuai.

Unsur tautan sebenarnya dapat diajarkan di bilik darjah, baik pada peringkat rendah mahupun pada peringkat menengah, dan bukan sekadar diajarkan pada peringkat universiti sahaja, atau 
dibuat kajian oleh ahli linguistik sahaja (Khathijah Abdul Hamid, 2001). Oleh itu, kajian ini akan melihat model pengajaran tautan yang sesuai digunakan dalam pengajaran dan pembelajaran bahasa Melayu peringkat menengah rendah.

\section{TUJUAN KAJIAN}

Tujuan kajian ini adalah untuk mengenal pasti keberkesanan pengajaran model pengajaran unsur tautan terhadap pencapaian karangan bahasa Melayu. Oleh itu, objektif kajian ini akan menjawab soalan-soalan berikut:

1) Adakah terdapat perbezaan yang signifikan antara pencapaian murid kumpulan eksperimen dengan pencapaian murid kumpulan kawalan dari segi jumlah unsur tautan dalam karangan mereka pada peringkat ujian pra?

2) Adakah terdapat perbezaan yang signifikan antara pencapaian murid kumpulan eksperimen dengan pencapaian murid kumpulan kawalan dari segi jumlah unsur tautan dalam karangan mereka pada peringkat ujian pasca?

\section{MODEL TAUTAN}

\section{Model Tautan Halliday dan Hasan}

Analisis teks atau analisis wacana, terutamanya dalam aspek kohesi dan koheren dipengaruhi oleh sebahagian besarnya oleh Halliday dan Hasan (1976). Menurut mereka, organisasi sesuatu teks terbina daripada intersentential linguistic features (ciri-ciri yang membina teks), yang memberikan sesuatu teks itu tekstur, dan ciri yang membina teks tersebut wujud di dalam teks (Halliday, 1994). Halliday dan Hasan (1976) menamakan ciri linguistik tersebut sebagai cohesive ties (unsur tautan/sarana kohesi). Halliday dan Hasan (1976) membahagikan tautan kepada lima jenis, iaitu rujukan, penggantian, elipsis, penghubung, dan tautan leksikal.

Nik Safiah et al. (2008) juga menggunakan penjenisan kohesi (tautan) oleh Halliday dan Hassan (1976) tetapi menggunakan istilah penanda wacana untuk semua unsur tautan (sarana kohesi/ cohesive ties). Menurut mereka, penanda wacana terdiri daripada penanda 
penghubung, penanda rujukan, penanda penggantian, penanda leksikal, dan penanda elipsis atau pengguguran. Penggunaan istilah penanda wacana untuk merujuk kepada semua jenis unsur tautan mungkin akan mengelirukan pengguna bahasa Melayu, khususnya guru dan murid. Hal ini kerana mereka sudah biasa dengan istilah penanda wacana yang bermaksud sentence connectors dan sequence connectors dalam tatabahasa bahasa Inggeris sebagai kata atau frasa yang berada di permulaan ayat yang biasanya diletakkan tanda koma (,) selepasnya. Menurut Sanat Md. Nasir (2002), tautan penghubung ayat (sentence connectors) berfungsi untuk menghubungkan antara unsur linguistik, iaitu unit teks (ayat) sebelum dengan yang sesudahnya.

\section{Model Tautan Pindaan Sanat Md. Nasir}

Model Tautan Pindaan Sanat Md. Nasir (2002) menggunakan perkataan 'pindaan' dengan maksud pada asalnya ialah Model Halliday dan Hasan (1976), tetapi telah mengalami penyusunan semula, tambahan dan penekanan aspek tertentu dalam kajian tautan aliran sistemik (systemic theory). Sanat Md. Nasir (2002) membahagikan tautan kepada tiga jenis utama, iaitu tautan perulangan, tautan kolokasi, dan tautan penghubung ayat. Tautan perulangan menunjukkan ciri, sama ada bentuk unsur linguistik yang berulang, atau dari segi makna unsur itu yang berulang, atau kedua-duanya sekali.

Tautan kolokasi tidak melibatkan unsur linguistiknya berulang dari segi bentuk dan makna. Tautan jenis ini merujuk kepada konteksnya, iaitu 'keberadaan' sesuatu unsur linguistik dengan yang lain antara dua unit teks. Keberadaan ini melibatkan domain makna. Perspektif berdasarkan domain makna inilah keberadaan unsur linguistik yang terlibat dijeniskan lagi kepada empat jenis.

Tautan penghubung ayat pula berfungsi untuk menghubungkan antara unsur linguistik, iaitu unit teks sebelum dengan yang sesudahnya. Menurut Sanat Md. Nasir (2002), penghubung itu sendiri bukan unsur tautan tetapi berfungsi menghubungkan unsur tautan. Hal ini berdasarkan kriteria makna, penghubung ayat dapat dijeniskan kepada lima.

Skema jenis tautan utama dengan subjenis masing-masing dapat ditunjukkan dalam Jadual 1. 
Jadual 1

Model Tautan Pindaan Sanat Md. Nasir (2002)

\begin{tabular}{ll}
\hline Jenis Tautan Utama & Subjenis Tautan \\
\hline A. Tautan Perulangan & 1. Tautan Perulangan Rujukan \\
& 2. Tautan Perulangan Penggantian \\
& 3. Tautan Perulangan Elipsis \\
& 4. Tautan Perulangan Leksikal \\
& 5. Tautan Perulangan Parafrasa \\
& 6. Tautan Perulangan Paralelisme \\
& 7. Tautan Perulangan Struktur dan Makna Sama \\
B. Tautan Kolokasi & 1. Tautan Kolokasi Antoniman \\
& 2. Tautan Kolokasi Kohiponiman \\
& 3. Tautan Kolokasi Hasil \\
& 4. Tautan Kolokasi Sifat \\
C. Tautan Penghubung & 1. Tautan Penghubung Ayat Tambahan \\
Ayat & 2. Tautan Penghubung Ayat Tentangan \\
& 3. Tautan Penghubung Ayat Sebab-Musabab \\
& 5. Tautan Penghubung Ayat Waktu \\
\end{tabular}

\section{Model Pengajaran Unsur Tautan}

Jenis unsur tautan yang digunakan dalam Model Pengajaran Unsur Tautan ini berdasarkan Model Tautan Pindaan Sanat Md. Nasir (2002). Namun, model ini cuba mengelakkan daripada membebankan pelajar dengan penggunaan istilah linguistik yang sukar difahami. Penggunaan istilah yang sukar akan mengelirukan pelajar (Cook, 1989). Oleh itu, penggunaan istilah yang dipermudah amat perlu sebagai usaha agar dapat difahami dan diterima oleh pelajar (Khathijah Abdul Hamid, 2001). Oleh sebab istilah dan pembahagian jenis tautan yang dikemukakan dalam Model Tautan Pindaan Sanat Md. Nasir (2002) agak sukar difahami oleh pelajar sekolah, maka beberapa pengubahsuaian terpaksa dibuat sesuai dengan tahap mereka.

Perubahan tersebut ialah tautan perulangan rujukan dan penggantian digabungkan menjadi perulangan rujukan. Tautan perulangan leksikal, parafrasa, dan struktur dan makna sama digabungkan dan diubah istilah kepada dua, iaitu perulangan sama, dan perulangan sama maksud.

Istilah tautan kolokasi antoniman digantikan dengan hubungan berlawanan. Istilah tautan kolokasi kohiponiman digantikan dengan hubungan keluarga, dan hubungan sebab-akibat menggantikan 
tautan kolokasi hasil. Istilah penghubung ayat tidak diubah kerana pelajar sudah biasa menggunakan tautan jenis ini dalam karangan mereka. Penghubung ayat lebih dikenali oleh pelajar sebagai penanda wacana (sentence connectors dan sequence connectors).

Unsur tautan dalam Model Tautan Pindaan Sanat Md. Nasir yang tidak disentuh dalam model ini ialah tautan perulangan paralelisme dan elipsis, serta tautan kolokasi sifat. Tautan ini tidak disentuh kerana jarang digunakan dan akan mengelirukan pelajar sekiranya diajarkan pada peringkat sekolah. Sebenarnya, semua unsur yang dipilih untuk diguna pakai dalam model ini sudah cukup untuk menjadikan karangan pelajar lebih kohesif, koheren dan berkualiti.

Senarai istilah dan pembahagian jenis unsur tautan yang digunakan dalam Model Pengajaran Unsur Tautan ini ditunjukkan dalam Jadual 2.

Jadual 2

Jenis Tautan dalam Model Pengajaran Unsur Tautan

\begin{tabular}{ll}
\hline Jenis Tautan & Subjenis Tautan \\
\hline A. Tautan Perulangan & 1. Perulangan Sama \\
& 2. Perulangan Sama Maksud \\
& 3. Perulangan Rujukan \\
B. Tautan Hubungan & 1. Hubungan Berlawanan \\
& 2. Hubungan Keluarga \\
& 3. Hubungan Sebab-akibat \\
C. Tautan Penghubung Ayat & 1. Penghubung Ayat Tambahan \\
& 2. Penghubung Ayat Tentangan \\
& 3. Penghubung Ayat Musabab \\
& 4. Penghubung Ayat Waktu \\
& 5. Penghubung Ayat Terusan \\
& (i) Turutan \\
& (ii) Contoh \\
& (iii) Kesimpulan \\
& (iv) Umum \\
\hline
\end{tabular}

A. Tautan Perulangan

(i) Perulangan Sama

Dalam sesuatu perenggan karangan, terdapat kata dan frasa yang diulang banyak kali. Perulangan kata dan frasa sama ialah cara yang 
digunakan oleh penulis untuk kekal membincangkan sesuatu topik dan memastikan perenggan tersebut kohesif dan koheren. Melalui perulangan kata dan frasa sama, pengaliran idea utama dalam ayat topik dan idea-idea yang menyokongnya dalam ayat-ayat huraian mudah diikuti oleh pembaca.

Contoh penggunaan perulangan sama dapat ditunjukkan dalam perenggan di bawah:

(1)Salah satu cara memupuk semangat kejiranan adalah dengan mengamalkan nilai-nilai murni kejiranan. (2)Antara nilai murni kejiranan yang patut diamalkan adalah seperti mengutamakan kepentingan dan kebaikan bersama jiran, mengamalkan nilai bertolak ansur, hormat-menghormati dan bantumembantu. (3)Kita mesti bertegur sapa dengan jiran dan sentiasa membantu jiran ketika jiran memerlukan pertolongan dengan kita, seperi semasa kenduri-kendara dan sebagainya. (4)Selain itu, kita perlu menjaga tingkah laku agar tidak menyakiti hati jiran kita. (5) Kita juga tidak perlu memikirkan atau membesarkan perkara yang remeh-temeh yang boleh merosakkan hubungan kita dengan jiran. (6)Nilai-nilai murni kejiranan ini patut diamalkan oleh setiap anggota masyarakat supaya semangat kejiranan sentiasa segar dan sebati dalam diri setiap individu.

Dalam perenggan di atas, kata kunci yang terdapat dalam ayat topik ialah semangat kejiranan dan nilai-nilai murni kejiranan. Oleh itu, perkataan jiran diulang sebanyak 6 kali, frasa nilai-nilai murni kejiranan diulang sebanyak $3 \mathrm{kali}$, dan frasa semangat kejiranan diulang sebanyak 2 kali. Perkataan dan frasa tersebut bertaut dengan kata dan frasa yang sama dalam ayat-ayat sebelum untuk membentuk jalinan idea yang berkait antara satu sama lain. Oleh itu, pengaliran idea menjadi lancar dan tumpuan pembaca hanya pada perkataan dan frasa yang diulang-ulang tersebut.

Tautan perulangan sama bagi ayat-ayat di atas adalah seperti berikut:

'...nilai murni kejiranan...' dalam ayat (2) bertaut dengan '...nilai-nilai murni kejiranan dalam ayat (1),

'...jiran...' dalam ayat (2) bertaut dengan '...kejiranan' dalam ayat (1),

...jiran(i) dalam ayat (3) bertaut dengan '...jiran...' dalam ayat (2), 
'...jiran...'(ii) dalam ayat (3) bertaut dengan '...jiran...'(i) dalam ayat (3),

'...jiran...'(iii) dalam ayat (3) bertaut dengan '...jiran...'(ii) dalam ayat (3),

'...jiran...' dalam ayat (4) bertaut dengan '...jiran...'(iii) dalam ayat (3),

'...jiran' dalam ayat (5) bertaut dengan '...jiran...' dalam ayat (4),

'Nilai-nilai murni kejiranan...' dalam ayat (6) bertaut dengan '...nilai murni kejiranan' dalam ayat (2), dan '...semangat kejiranan...' dalam ayat (6) bertaut dengan '... semangat kejiranan...dalam ayat (1).

Perulangan sama termasuklah:

(a) Perulangan kata sama:

Contoh:

pencemaran ... dengan ... pencemaran

pelajar ... dengan ...pelajar

kemalangan ... dengan ... kemalangan

(b) Perulangan kata dasar sama:

Contoh:

pencemaran ... dengan ... tercemar

merokok ... dengan ...perokok

guru ... dengan ... guru-guru

disalah guna ... dengan ... penyalahgunaan

(c) Perulangan frasa sama:

Contoh:

generasi muda ... dengan ... generasi muda

pihak sekolah ... dengan ... pihak sekolah

memandu kenderaan ... dengan ... memandu kenderaan

(d) Perulangan klausa dan ayat sama:

Contoh:

keadaan jalan raya pada musim hujan ... dengan ... keadaan jalan raya pada musim hujan 
perkara yang perlu diutamakan oleh pihak kerajaan ... dengan ... perkara yang perlu diutamakan oleh pihak kerajaan

\section{(ii) Perulangan Sama Maksud}

Perulangan sama maksud ialah cara yang digunakan untuk mengatasi masalah penggunaan perulangan sama yang berlebihlebihan yang akan membosankan pembaca kerana bersifat monotonous. Contoh penggunaan perulangan sama maksud:

\section{(1)Tidak dapat dinafikan bahawa wang merupakan} faktor utama yang mendorong seseorang itu terlibat dalam kegiatan jenayah. (2)Tanpa duit, hidup kita akan menjadi susah dan terpinggir. (3)Oleh itu, manusia sanggup membuat apa-apa sahaja untuk memperoleh wang, lebih-lebih lagi ketika berhadapan dengan masalah kewangan, atau keinginan untuk mendapatkan wang dengan cara mudah. (4)Golongan penjenayah sanggup terlibat dalam perbuatan yang menyalahi undangundang seperti merompak, mencuri, ragut, dan pecah rumah semata-mata untuk memperoleh wang tanpa bersusah-payah. (5)Bagi mereka, wang adalah segalagalanya.

Dalam perenggan di atas, perkataan duit dalam ayat (2) bertaut dengan wang dalam ayat (1), frasa mendapatkan wang dalam ayat (3) bertaut dengan memperoleh wang dalam ayat (3), frasa perbuatan yang menyalahi undang-undang dalam ayat (4) bertaut dengan kegiatan jenayah dalam ayat (1), dan frasa memperoleh wang tanpa bersusah-payah dalam ayat (4) bertaut dengan mendapatkan wang dengan cara mudah dalam ayat (3).

(iii) Perulangan Rujukan

Rujukan digunakan untuk merujuk atau menggantikan sesuatu kata atau frasa dalam ayat sebelum, atau dalam ayat yang sama. Tujuan perulangan rujukan digunakan adalah untuk 'mengikat' unsur rujukan tersebut dengan kata atau frasa sebelum. Dengan adanya rujukan tersebut, maka ayat-ayat yang terhasil dalam sesuatu perenggan akan bertaut antara satu sama lain. Contoh penggunaan perulangan rujukan: 
(1)Masalah alam sekitar berpunca daripada sikap rakyat sendiri. (2)Kita sering bersikap lepas tangan atau tidak kisah apabila berhadapan dengan masalah ini. (3)Sebagai contohnya, terdapat ibu bapa yang membiarkan sahaja anak-anak mereka membuang sampah sesuka hati. (4)Sikap sedemikian sudah tentu akan memburukkan masalah tersebut.

Perenggan tersebut merupakan perenggan yang kohesif dan koheren. Hal ini demikian kerana isu yang terdapat dalam ayat topik, iaitu masalah alam sekitar dan idea utama, iaitu sikap rakyat dipertautkan dengan ayat-ayat berikutnya dengan menggunakan rujukan, iaitu:

'Kita...' dalam ayat (2) bertaut dengan '...rakyat...' dalam ayat (1),

'...masalah ini.' dalam ayat (2) bertaut dengan _Masalah alam sekitar...' dalam ayat (1),

'...mereka' dalam ayat (3) bertaut dengan '...ibu bapa...' dalam ayat (3) dan '... rakyat... dalam ayat (1),

'Sikap sedemikian...' dalam ayat (4) bertaut dengan '... membiarkan sahaja anak-anak mereka membuang sampah sesuka hati' dalam ayat (3) dan '...bersikap lepas tangan atau tidak kisah...' dalam ayat (2), dan '...masalah tersebut' dalam ayat (4) bertaut dengan 'Masalah alam sekitar...' dalam ayat (1).

Unsur-unsur perulangan rujukan yang biasa terdapat dalam bahasa Melayu ialah seperti kita, mereka, begitu, begini, demikian, ini, itu, sana, sini situ, dan tersebut.

Contoh-contoh penggunaan unsur rujukan ialah:

...perkara ini...

...hal tersebut...

...perbuatan sedemikian...

\section{B. Tautan Hubungan}

(i) Hubungan Berlawanan

Hubungan berlawanan bermaksud hubungan unsur tautan yang bercirikan makna berlawanan. Dalam kehidupan seharian, kita sering 
membandingkan atau membincangkan perkara yang berlawanan. Oleh itu, dalam sesuatu perenggan yang membincangkan perbandingan antara dua entiti atau keadaan, biasanya penulis akan menggunakan tautan hubungan berlawanan contoh.

(i) “....Pekerja tempatan biasanya menuntut gaji yang tinggi. Untuk mengurangkan kos. majikan lebih suka mengupah pekerja asing yang gajinya jauh lebih rendah. ..."

Dalam contoh (i) di atas, perkataan rendah bertaut dengan tinggi, dan frasa pekerja asing bertaut dengan pekerja tempatan dalam ayat sebelum dari segi hubungan berlawanan.

(ii) "... . Semangat kejiranan masih diamalkan oleh masyarakat kampung. Sebaliknya, semangat ini semakin luntur dan tidak diamalkan oleh masyarakat bandar. ..."

Hubungan berlawanan dalam contoh (ii) di atas ialah frasa tidak diamalkan bertaut dengan masih diamalkan, dan masyarakat bandar bertaut dengan masyarakat kampung.

(iii) “... . Oleh sebab buah-buahan tempatan terus dapat dipasarkan sebaik-baik sahaja dipetik, maka buah-buahan tempatan lebih segar berbanding buah-buahan yang diimport. Buah-buahan yang diimport memakan masa yang lama sebelum sampai di negara kita. Oleh itu, buah-buahan yang diimport kurang segar berbanding dengan buahbuahan tempatan...."

Dalam contoh (iii) di atas, buah-buahan yang diimport bertaut dengan buah-buahan tempatan, dan kurang segar bertaut dengan lebih segar.

\section{(ii) Hubungan Keluarga}

Hubungan keluarga merujuk kepada keberadaan hubungan makna unsur yang bertaut di peringkat superordinat dengan ordinatnya, iaitu hubungan entiti menyeluruh dengan unsur sebahagian, atau hubungan unsur yang sebahagian dengan entiti menyeluruh. Rajah 1 menunjukkan pemahaman tentang maksud hubungan keluarga: 
Rajah 1. Hubungan Keluarga

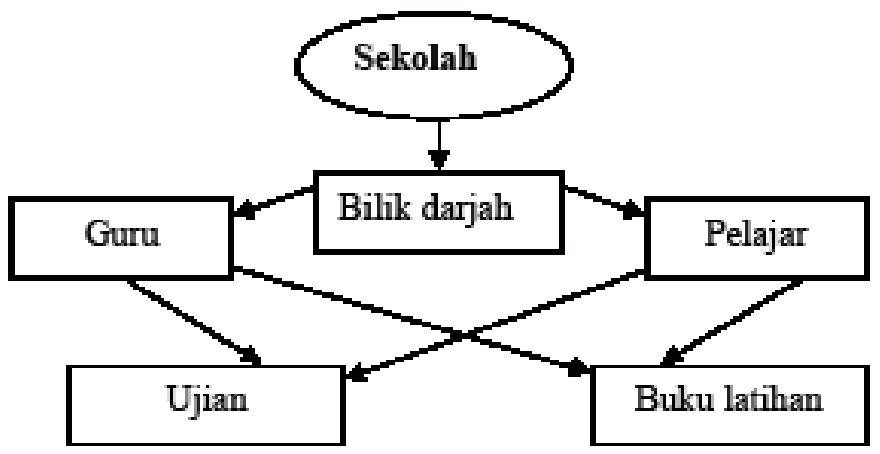

Dalam rajah 1, sekolah merupakan entiti menyeluruh (superordinat) manakala bilik darjah, guru, pelajar, ujian, dan buku latihan ialah unsur sebahagian (ordinat). Oleh itu, sekiranya sesuatu perenggan itu membincangkan isu kemerosotan disiplin pelajar, maka kata dan frasa dalam rajah di atas akan muncul dalam perenggan tersebut seperti contoh di bawah:

...sekolah ...bilik darjah ... guru ...pelajar ... buku latihan ... ujian ...

Tautan dari segi hubungan keluarga dapat dilihat dalam perenggan di bawah:

Terdapat juga remaja yang lari dari rumah kerana berhadapan dengan masalah keluarga yang porak-peranda. Apabila hal ini berlaku, perhatian dan tumpuan ibu bapa terhadap anak-anak amat kurang. Suasana sedemikian menyebabkan remaja tidak selesa berada di rumah. Mereka lebih senang berada di luar rumah dan lama-kelamaan mereka akan terus meninggalkan rumah untuk mencari ketenangan dan kedamaian.

Hubungan keluarga dalam perenggan juga merupakan salah satu teknik atau cara yang digunakan oleh penulis ketika memberikan contoh. Petikan perenggan di bawah menunjukkan bagaimana tautan hubungan keluarga digunakan oleh penulis untuk memberikan contoh. 
(i) ... .Pekerja asing yang bekerja di negara kita kebanyakannya datang dari negara-negara jiran kita. Sebagai contohnya, pengusaha kilang banyak mengambil pekerja dari Indonesia, Bangladesh, Myanmar, dan Vietnam. ...

(ii)... .Aktiviti penerokaan hutan menyumbang kepada pelbagai bencana alam, seperti banjir, tanah runtuh, dan pemanasan global. ...

(iii) Hubungan Sebab-Akibat

Hubungan sebab-akibat bermaksud tautan yang melibatkan keberadaan hubungan makna antara tautan yang satu menghasilkan yang lain. Oleh itu, hubungan sebab-akibat merupakan satu teknik yang selalu digunakan oleh penulis untuk menulis perenggan isi. Perenggan boleh dimulakan dengan sebab. Hal ini bermakna idea utama dimulakan dengan sebab, iaitu keadaan atau fenomena yang menyebabkan sesuatu itu berlaku, dan diikuti oleh akibat atau kesan daripada sebab, misalnya hujan lebat menyebabkan banjir dan tanah runtuh. Hubungan sebab-akibat tersebut dapat ditunjukkan seperti berikut.

...hujan lebat...banjir...tanah runtuh....

Selain itu, terdapat juga idea utama dalam sesuatu perenggan yang yang bermula dengan akibat dan diikuti oleh sebab, iaitu hubungan antara unsur yang dihasilkan oleh sesuatu keadaan atau fenomena. Dalam contoh hujan lebat tadi, idea utama dimulakan dengan akibat iaitu banjir dan tanah runtuh, dan akibat tersebut disebabkan oleh keadaaan atau fenomena hujan lebat. Hubungan akibat-sebab yang berlaku adalah seperti berikut:

...banjir...tanah runtuh...hujan lebat...

Perenggan di bawah mempunyai tautan hubungan sebab-akibat:

Pelajar yang kurang didikan agama merupakan antara punca wujudnya gejala samseng di sekolah. Hal ini kerana jika kurang didikan agama dalam diri seseorang pelajar itu, mereka terdorong kepada tingkah laku yang tidak baik. Mereka sering terlibat dalam perbuatan samseng seperti bergaduh, membuli pelajar yang lemah, dan merosakkan harta benda sekolah. 


\section{Tautan Penghubung Ayat}

Penghubung ayat atau penanda wacana ialah kata atau frasa yang berfungsi sebagai penghubung atau 'jambatan' yang membantu seseorang membaca dari satu ayat ke satu ayat dengan lancar. Penulis menamatkan suatu idea yang lengkap dalam satu ayat, dan menandakannya dengan tanda noktah di akhir ayat tersebut. Untuk memudahkan pembaca agar dapat mengaitkan ayat sebelum dengan ayat yang berikutnya, penulis memasukkan penghubung ayat sebagai 'jambatan' antara kedua-dua ayat tersebut.

Contoh penggunaan penghubung ayat dapat ditunjukkan dalam perenggan di bawah:

Golongan remaja merupakan aset penting negara sebagai pewaris negara pada masa akan datang. Namun, para remaja sering dikaitkan dengan pelbagai gejala negatif seperti masalah dadah, lepak, 'mat rempit', dan jenayah.

Tautan penghubung ayat berbeza dengan tautan perulangan dan tautan hubungan dari segi fungsi dan unsur yang bertaut. Tautan perulangan bertaut dengan kata, frasa dan klausa dalam ayat sebelum dari segi hubungan makna dan tatabahasa. Tautan hubungan bertaut dari segi keberadaan sesuatu unsur yang berkait. Tetapi tautan penghubung ayat tidak bertaut dengan kata, frasa, dan klausa tertentu dalam ayat sebelum. Sebaliknya, penghubung ayat berfungsi sebagai penghubung atau 'jambatan' antara ayat yang akan dibina dengan ayat sebelum. Penghubung ayat terletak di awal ayat dan biasanya diikuti dengan tanda koma.

Jenis-jenis penghubung ayat ialah:

\section{1) Penghubung Ayat Tambahan}

Contoh: Sekali lagi, Lebih-lebih lagi, Tambahan pula, Dalam hal ini juga,

\section{2) Penghubung Ayat Tentangan}

Contoh:Tetapi, Berbeza daripada, Sebaliknya, Walau bagaimana sekalipun, Namun,

\section{3) Penghubung ayat Musabab}

Contoh: Sebagai Kesannya, Sehubungan itu, Natijahnya, Oleh itu, Jadi, Akibatnya, 


\section{4) Penghubung Ayat Waktu}

Contoh: Akhirnya, Semenjak itu, Dewasa ini, Sementara itu, Selepas itu, Pada ketika itu,

\section{5) Penghubung Ayat Terusan}

\section{a. Turutan}

Contoh: Seterusnya, Keduanya, Akhirnya, Kemudiannya, Selepas itu,

b. Contoh

Contoh: Contohnya, Apa yang dimaksudkan, Misalnya, Umpamanya,

\section{c. Kesimpulan}

Contoh:Oleh itu, Ringkasnya, Jadi, Sebagai penggulungan, Pendek kata, Jelaslah bahawa, Rumusannya, Demikianlah, Kesimpulannya,

\section{d. Umum}

Contoh: Dengan ini, Lazimnya, Justeru, Amnya, Selaras dengan itu, Umumnya, Kebiasaannya, Sememangnya,

\section{METODOLOGI KAJIAN}

Kajian ini menggunakan reka bentuk kuasi eksperimen (QuasiExperimental Design). Keputusan untuk menggunakan reka bentuk ini dibuat kerana sampel kajian berdasarkan kelas yang sedia ada (intact class) tanpa diberi tugasan rawak (Ary, Jacobs, \& Razavieh, 2002). Reka bentuk kajian dijelaskan dalam Jadual 3.

Jadual 3

Reka Bentuk Kajian

\begin{tabular}{llll}
\hline Kumpulan Eksperimen & Praujian & $\mathrm{X}^{*}$ & Pascaujian \\
Kumpulan Kawalan & Praujian & $\mathrm{Y}^{*}$ & Pascaujian \\
\hline
\end{tabular}

$\mathrm{X} *$ : Pengajaran menggunakan Model Tautan selama enam minggu

$\mathrm{Y}^{*}$ : Pengajaran menggunakan pendekatan tradisional selama enam minggu

Pemboleh ubah bebas dalam kajian ini ialah pendekatan pengajaran yang digunakan bagi kumpulan eksperimen dan kumpulan kawalan. Sebanyak 60 orang orang murid tingkatan tiga di sebuah sekolah menengah di Kedah dipilih sebagai sampel kajian. 
Mereka dibahagikan kepada dua kumpulan, iaitu 30 orang dalam kumpulan eksperimen dan 30 orang dalam kumpulan kawalan. Murid kumpulan eksperimen menerima pendedahan tentang unsur tautan selama enam minggu melalui Model Pengajaran Unsur Tautan. Murid kumpulan kawalan tidak didedahkan dengan pengajaran unsur tautan. Mereka diajarkan tajuk karangan yang sama dengan kumpulan eksperimen tetapi diajarkan dengan kaedah biasa.

Instrumen kajian ialah karangan murid yang diberikan pada peringkat ujian pra dan ujian pasca. Pelajar diminta menulis dua karangan jenis fakta (ekspositori) yang panjangnya tidak kurang daripada 180 patah perkataan. Karangan pertama pada peringkat ujian pra dan karangan kedua pada peringkat ujian pasca. Tajuk karangan bagi ujian pra adalah berbeza dengan tajuk karangan pada peringkat kedua. Untuk menjawab soalan kajian, iaitu untuk mengukur perbezaan yang signifikan antara pencapaian murid kumpulan eksperimen dengan pencapaian pelajar kumpulan kawalan dari segi jumlah unsur tautan dalam karangan mereka pada peringkat ujian pra dan ujian pasca, jumlah unsur tautan dalam karangan murid dikira.

Untuk memastikan pelajar kumpulan eksperimen menerima rawatan yang sepatutnya, pengkaji sendiri telah mengajar kelas kumpulan eksperimen tersebut. Pengkaji memberikan rawatan selama enam minggu menggunakan Model Pengajaran Unsur Tautan yang telah disediakan. Bagi murid kumpulan kawalan pula, seorang guru Bahasa Melayu yang lain akan mengajar mereka selama enam minggu menggunakan tajuk karangan yang sama dengan karangan kumpulan eksperimen, tetapi menggunakan kaedah biasa.

Tempoh eksperimen hanya dijalankan untuk enam minggu sahaja bagi mengelakkan kajian ini daripada menerima terlalu banyak pengaruh pemboleh ubah ekstranus yang dapat mengganggu kesahan dalaman (internal validity) kajian. Sekiranya tempoh eksperimen diadakan lebih panjang, dikhuatiri faktor lain seperti latihan yang banyak, kelas tambahan yang diikuti, galakan daripada ibu bapa akan mempengaruhi pencapaian karangan murid dan bukannya disebabkan oleh pengajaran unsur tautan.

Selain itu, pengkaji juga tidak terlibat dalam pemeriksaan karangan pelajar pada peringkat ujian pra dan ujian pos untuk mendapatkan skor karangan mereka. Pemeriksaan karangan dilakukan oleh seorang guru Bahasa Melayu yang berpengalaman berdasarkan kriteria pemeriksaan yang standard, iaitu berdasarkan kriteria penskoran Bahasa Melayu Kertas 2 Penilaian Menengah Rendah (PMR) seperti yang ditetapkan oleh Lembaga Peperiksaan 
Malaysia (2005). Pengkaji tidak memaklumkan kepada pemeriksa tersebut tentang wujudnya kumpulan eksperimen dan kumpulan kawalan. Hal ini penting untuk mengelakkan bias (Ary, Jacobs \& Razavieh (2002).

Reka bentuk kuasi eksperimen menggunakan kelas sedia ada (intact class) bagi membentuk kumpulan eksperimen dan kumpulan kawalan. Oleh itu, masalah memastikan wujudnya kesahan luaran (external validity) dapat diatasi kerana kedua-dua kumpulan tidak berada di kelas yang sama.

Data dalam kajian ini dianalisis menggunakan program SPSS for Windows Version 11.5. Ujian-t sampel bebas (independent samples $t$-test) digunakan untuk menjawab soalan kajian iaitu untuk menentukan sama ada terdapat perbezaan yang signifikan antara pencapaian murid kumpulan eksperimen dengan pencapaian murid kumpulan kawalan dari segi jumlah unsur tautan pada peringkat ujian pra dan ujian pasca.

\section{DAPATAN}

Pada peringkat ujian pra, dapatan kajian mendapati tidak terdapat perbezaan yang signifikan antara jumlah unsur tautan bagi murid kumpulan eksperimen dan jumlah unsur tautan murid kumpulan kawalan. Hasil ujian-t yang dijalankan ditunjukkan dalam jadual 4.

Jadual 4

Keputusan Ujian-t: Jumlah Unsur Tautan Kumpulan Eksperimen dan Kumpulan Kawalan pada Peringkat Ujian Pra

\begin{tabular}{llccccc}
\hline & Kumpulan & $\mathrm{N}$ & Min & $\begin{array}{c}\text { Sisihan } \\
\text { Piawai }\end{array}$ & $\mathrm{t}$ & $\begin{array}{c}\text { Sig 2 } \\
\text { hujung }\end{array}$ \\
\hline Jumlah Tautan & Eksperimen & 30 & 29.00 & 6.46 & 0.22 & 0.83 \\
& Kawalan & 30 & 28.60 & 7.66 & & \\
\hline
\end{tabular}

$* \mathrm{p}<0.05$

Pada peringkat ujian pasca, dapatan kajian menunjukkan terdapat perbezaan yang signifikan antara jumlah unsur tautan bagi murid kumpulan eksperimen dan jumlah unsur tautan murid kumpulan kawalan. Pada peringkat ini, murid kumpulan eksperimen telah menunjukkan peningkatan yang sangat ketara dalam jumlah unsur tautan berbanding dengan jumlah unsur tautan murid kumpulan kawalan. 
Jadual 5

Keputusan Ujian-t: Jumlah Unsur Tautan Kumpulan Eksperimen dan Kumpulan Kawalan pada Peringkat Ujian Pasca

\begin{tabular}{llcrrrc}
\hline & Kumpulan & $\mathrm{N}$ & Min & $\begin{array}{c}\text { Sisihan } \\
\text { Piawai }\end{array}$ & $\mathrm{t}$ & $\begin{array}{c}\text { Sig 2 } \\
\text { hujung }\end{array}$ \\
\hline Jumlah Tautan & Eksperimen & 30 & 57.23 & 13.42 & 7.51 & 0.00 \\
& Kawalan & 30 & 34.43 & 9.83 & & \\
\hline
\end{tabular}

$* \mathrm{p}<0.05$

\section{PERBINCANGAN}

Pada peringkat ujian pra, didapati pencapaian jumlah unsur tautan bagi kumpulan eksperimen dan kumpulan kawalan adalah hampir sama. Min jumlah unsur tautan bagi kumpulan eksperimen ialah sebanyak 29.00, manakala min jumlah unsur tautan bagi kumpulan kawalan adalah sebanyak 28.60. Oleh itu, ujian-t yang dijalankan menunjukkan tidak ada perbezaan yang signifikan dari segi jumlah unsur tautan bagi kedua-dua kumpulan tersebut pada peringkat ujian pra.

Pada peringkat ujian pasca, didapati jumlah unsur tautan bagi pelajar kumpulan eksperimen telah menunjukkan peningkatan yang begitu ketara. Min jumlah unsur tautan bagi kumpulan eksperimen ialah sebanyak 57.23, manakala min jumlah unsur tautan bagi kumpulan kawalan adalah sebanyak 34.43. Keputusan ujian-t yang dijalankan menunjukkan terdapat perbezaan yang signifikan dari segi jumlah unsur tautan bagi kedua-dua kedua-dua kumpulan tersebut pada peringkat ujian pasca.

Dapatan kajian pada peringkat ujian pasca ini menyokong kajian yang dibuat oleh Abdul Jalil Othman (2000) bahawa terdapat perbezaan keupayaan dan kebolehan murid dalam menghasilkan kepelbagaian unsur tautan setelah unsur tautan diajarkan. Dalam hal ini, keupayaan murid kumpulan eksperimen telah meningkat setelah diberikan pendedahan tentang unsur tautan. Dapatan ini menyokong pendapat Khathijah Abdul Hamid (2001) dalam kajian beliau bahawa pengajaran tautan yang diajarkan kepada murid secara sedar, dan dipermudah istilahnya dapat membantu murid untuk menghasilkan perenggan karangan yang kohesif dan koheren. Selain itu, dapatan ini juga membuktikan pendapat Chapman (1983) dalam Wong Khek Seng (1993) bahawa unsur tautan mempunyai potensi untuk diajarkan di bilik darjah secara lebih berkesan dan praktikal. 
Berdasarkan dapatan kajian pada peringkat ujian pra dan ujian pasca, dapat disimpulkan bahawa pengajaran unsur tautan dapat membantu murid untuk menghasilkan perenggan yang kohesif dan koheren. Penentuan terhadap penghasilan perenggan yang kohesif dan koheren tersebut adalah dengan membuat analisis kekerapan penggunaan unsur tautan yang terdapat dalam karangan. Kaedah analisis kekerapan unsur tautan ini digunakan oleh pengkaji seperti Musmira Sa'ad (1995), Abdul Jalil Othman (2000), Lucas dan Weasenforth (2001), Sanat Md. Nasir (2002) dan Bayatee Dueraman (2007). Lebih kerap unsur tautan digunakan dalam sesuatu teks, bermaksud jarak unsur tautan yang bertaut di dalam ayat atau antara ayat menjadi lebih dekat. Lebih dekat jarak setiap unsur tautan tersebut bertaut akan menjadikan sesuatu perenggan itu lebih kohesif dan koheren.

\section{IMPLIKASI KAJIAN}

Beberapa implikasi terhasil daripada kajian ini. Secara umumnya, implikasi kajian dapat dibahagikan kepada dua, iaitu implikasi terhadap teori dan implikasi terhadap praktis.

Dari segi teori, kajian ini telah membuktikan bahawa model tautan yang diperkenalkan oleh Halliday dan Hasan (1976) bukan sahaja dapat digunakan untuk bahasa Inggeris, tetapi dapat juga diaplikasikan dalam bahasa Melayu. Hal ini kerana bahasa Melayu juga mempunyai unsur-unsur tautan seperti yang dikemukakan oleh mereka. Pengkaji seperti Musmira Sa'ad (1995), Abdul Jalil Othman (2000), dan Khathijah Abdul Hamid (2001) yang berminat tentang tautan dalam bahasa Melayu menggunakan model Halliday dan Hasan (1976) dalam kajian mereka. Namun begitu, beberapa penyesuaian terpaksa dibuat dari segi penjenisan dan istilah untuk memungkinkan unsur tautan ini dapat diterima dalam pengajaran dan pembelajaran bahasa Melayu.

Dapatan kajian ini juga telah memberikan implikasi terhadap teori pengajaran bahasa Melayu di Malaysia. Pengajaran bahasa Melayu di sekolah, khususnya pengajaran tatabahasa terlalu berpegang kepada teori transformasi generatif yang diperkenalkan oleh Noam Chomsky pada tahun 1957. Menurut Cook (1989), pengajaran bahasa bukan sekadar menentukan betul atau salah sesuatu kata, frasa atau ayat berdasarkan rumus tatabahasa tertentu. Sebaliknya pengajaran bahasa harus mengambil kira peranannya secara keseluruhan, iaitu sebagai alat komunikasi. Dalam komunikasi 
manusia, sama ada secara lisan atau tulisan, komunikasi tersebut tidak berlaku sekadar satu ayat. Komunikasi berlaku melangkaui ayat sehingga membentuk suatu wacana. Oleh itu, guru perlu mengambil kira faktor wacana dan analisis wacana sekiranya mahu melahirkan pelajar yang mempunyai kecekapan berbahasa.

Dari segi praktis, kajian ini mendapati pengajaran unsur tautan telah menunjukkan kesan yang memberangsangkan dalam menghasilkan perenggan karangan yang kohesif dan koheren. Oleh itu, kajian ini telah memberikan implikasi terhadap aspek pelaksanaannya di bilik darjah. Implikasi tersebut adalah dari segi kesediaan guru, aspek pelaksanaan di bilik darjah, dan aspek penilaian.

Dalam usaha untuk memungkinkan unsur tautan dapat diajarkan dalam mata pelajaran Bahasa Melayu, para guru harus didedahkan dengan unsur tautan. Dalam hal ini, unsur tautan sepatutnya diberi penekanan kepada bakal-bakal guru bahasa Melayu. Pengetahuan tentang unsur tautan boleh juga disebarkan kepada para guru bahasa Melayu melalui kursus dan seminar.

Dalam aspek pelaksanaannya di bilik darjah, guru boleh merancang pelbagai aktiviti untuk mengajarkan unsur tautan ini. Aktiviti yang diadakan itu berdasarkan prinsip daripada mudah kepada susah. Aktiviti yang mudah untuk tautan perulangan adalah seperti menyenaraikan seberapa banyak kata yang dapat diterbitkan dari satu kata dasar, memberikan perkataan atau frasa yang sama maksud (sinonim) dengan perkataan atau frasa tertentu, dan menggantikan kata atau frasa dalam perenggan dengan unsur rujukan yang sesuai. Bagi tautan hubungan pula, aktiviti yang mudah adalah seperti memberikan perkataan atau frasa yang berlawan (antonim) dengan kata atau frasa tertentu untuk hubungan berlawanan, dan menyatakan superordinat (entiti menyeluruh) bagi senarai beberapa subordinat (entiti sebahagian) atau sebaliknya untuk hubungan keluarga. Bagi hubungan sebab-akibat pula, guru boleh menyediakan aktiviti mudah seperti murid dikehendaki menyenaraikan kesan atau akibat sesuatu keadaan, dan sebaliknya, iaitu menyenaraikan punca atau sebab sesuatu akibat itu berlaku.

Setelah murid dapat memahami konsep dan jenis tautan, guru bolehlah beralih kepada aktiviti yang lebih sukar. Antara aktiviti yang dapat dijalankan pada tahap ini adalah seperti mengaplikasikan unsur tautan dalam penulisan mereka, membetulkan kesilapan penggunaan unsur tautan, dan membuat analisis unsur tautan dalam perenggan atau dalam karangan. Analisis yang dapat dibuat adalah seperti menganalisis kekerapan sesuatu unsur tautan itu 
digunakan, dan membuat analisis jarak sesuatu unsur tautan itu bertaut dengan kata atau frasa sebelum. Pada peringkat ini, murid perlu menggunakan kemahiran berfikir, iaitu salah satu aspek yang ditekankan dalam pengisian kurikulum Sukatan Pelajaran Bahasa Melayu Kurikulum Bersepadu Sekolah Menengah (2003).

Kajian ini juga memberikan implikasi terhadap aspek penilaian sesuatu hasil karangan. Ketika memeriksa karangan, guru sepatutnya mengambil kira aspek kohesi dalam menentukan skor keseluruhan karangan tersebut. Antara perkara yang dapat dinilai tentang aspek kohesi ini ialah kekerapan unsur tautan yang digunakan, sama ada kurang, cukup, atau digunakan secara berlebihan. Penggunaan unsur tautan yang kurang menyebabkan karangan menjadi tidak kohesif, manakala penggunaan yang berlebihan pula akan menyebabkan karangan menjadi tidak menarik dan membosankan. Jarak unsur tautan juga boleh dipertimbangkan untuk dinilai. Guru memberikan skor yang tinggi sekiranya ayat-ayat mempunyai jarak tautan yang dekat. Karangan yang mempunyai jarak tautan yang jauh akan mendapat skor yang rendah. Akhir sekali, aspek kesilapan menggunakan unsur tautan juga dapat dijadikan kriteria dalam menilai karangan pelajar. Guru sepatutnya dapat mengesan penggunaan unsur tautan yang salah atau kurang tepat, dan membetulkan kesilapan tersebut.

\section{KESIMPULAN}

Dapatan kajian mendapati bahawa pengajaran unsur tautan dengan menggunakan Model Pengajaran Unsur Tautan telah memberikan kesan terhadap kebolehan murid kumpulan eksperimen dalam menghasilkan sejumlah besar unsur tautan dalam karangan mereka dalam usaha menghasilkan perenggan karangan yang kohesif dan koheren. Berdasarkan penemuan kajian ini dan kajian-kajian terdahulu, didapati unsur tautan perlu didedahkan kepada murid dalam penulisan karangan. Pengajaran unsur tautan menjadi pelengkap kepada pengajaran tatabahasa ayat yang menumpukan aspek rumus tatabahasa dan hanya terbatas setakat peringkat ayat. Di samping mengambil kira faktor pemboleh ubah lain seperti faktor tempoh pengajaran, kematangan, kecerdasan, pembacaan yang luas, kaedah pengajaran guru, dan latihan yang banyak, unsur tautan dapat diajarkan di bilik darjah dengan menggunakan istilah yang dipermudah dan dipelbagaikan aktiviti pengajaran berdasarkan prinsip dari mudah ke susah. Pengajaran unsur tautan mampu mewujudkan pertautan antara ayat-ayat dan perenggan sehingga terhasil karangan yang kohesif dan koheren. 


\section{RUJUKAN}

Abdul Jalil Othman. (2000). Analisis tautan ayat dari segi kohesi nahuan dan leksikal dalam penulisan karangan. Jurnal Bahasa, 44, 826-845.

Ary, D., Jacobs, L.C., \& Razavieh, A. (2002). Introduction to research in education (6th ed). California: Wadsworth/Thomson Learning.

Azhar M. Simin. (1988). Discourse-syntax of "Yang" in Malay (Bahasa Malaysia). Kuala Lumpur: Dewan Bahasa dan Pustaka.

Bayatee Dueraman. (2007). Cohesion and coherence in English essays written by Malaysian and Thai medical students. Proceedings from Southern Thailand English Language Teaching/Cultural Change Conference.

Beaugrande, R., \& Dressler, W. (1994). Introduction to text linguistics. London: Longman.

Cook, G. (1989). Discourse. Oxford: Oxford University Press.

Halliday, M.A.K. (1994). An introduction to functional grammar (2nd ed.). London: Arnold.

Halliday, M. A. K., \& Hasan, R. (1976). Cohesion in English. London: Longman.

Khathijah Abdul Hamid. (2001). Wacana dalam teks penulisan pertautan dalam karangan bahasa Melayu berdasarkan analisis kohesi dan koheren. Dewan Bahasa, 12, 31-38.

Lembaga Peperiksaan Malaysia. (2005). Bahasa Melayu PMR: Format pentaksiran mulai 2005. Kuala Lumpur: Kementerian Pelajaran Malaysia.

Lucas, S.B., \& Weasenforth, D. (2001). E-mail and word processing in the ESL classroom: How the medium affects the message. Language Learning \& Technology, 5, 135-165.

Musmira Sa'ad. (1995). Analisis tautan dalam cerpen "Kasih Datuk Bertaut": Suatu tinjauan awal. Jurnal Dewan Bahasa, 5, 405-425.

Nik Safiah Karim, Hashim Musa, Hamid Mahmood \& Farid M. Onn. (2008). Tatabahasa dewan edisi ketiga. Kuala Lumpur: Dewan Bahasa dan Pustaka.

Sanat Md. Nasir. (2002). Tautan dalam wacana bahasa Melayu akhbar. Kuala Lumpur: Dewan Bahasa dan Pustaka.

Sukatan Pelajaran Kurikulum Bersepadu Sekolah Menengah: Bahasa Melayu. (2003). Kuala Lumpur: Kementerian Pelajaran Malaysia.

Wong Khek Seng. (1993). Pautan dan pembinaan teks dalam bahasa Melayu: Satu tinjauan awal. Jurnal Bahasa, 4, 306- 313. 